\title{
The Transboundary Movement of Hazardous Waste: A Contribution to Improve the Present Technical-Judicial Model
}

\author{
Giancarlo Carosso, Cesare Luceri and Pierpaolo Oreste \\ Department of Environment Land and Infrastructure Engineering, Faculty of Engineering, \\ Politecnico di Torino, Corso Duca degli Abruzzi 24, 10129 Torino, Italy
}

Received 2012-06-13; Revised 12-07-04; Accepted 2012-07-13

\begin{abstract}
The expression "the transboundary movement of hazardous waste" refers, from the technical point of view, to a series of phases that begin with the creation of a hazardous waste and includes its identification according to international, regional and national standards, its delivery to specialized companies and its movement from the exporting country to the importing country; these phases end with the final destination of the waste (disposal or recovery). From the judicial point of view, this same expression means a set of international regulations, at the UN level, a judicial model constituted by various Multilateral Environmental Agreements-MEAs and in particular the Basel, Rotterdam and Stockholm Conventions. In spite of this model, an international market, dominated in certain strategic points by a chain of organized crime, has become established over the last 30 years, with consequent adverse effects on human health and the environment as well as on trade and competition. The illegal movement and transport of hazardous goods and waste undermine international policies and enforcement efforts and put law-abiding businesses at an economic disadvantage. It is here taken into account that there are in fact two judicial models that have to be referred to. Apart from the previously mentioned one, it is necessary to take into consideration the international judicial hazardous goods and waste transport model. The former model is examined (1) from a general point of view and during the various phases; (2) as far as the controls that the international regulations foresee along the chain are concerned; (3) with a case study concerning the PCB category, a category which is very vast and whose contents are sometimes considered as hazardous goods and sometimes as wastes. Because of the great complexity of the problems and in order to have a clear picture, a specific second study, which is closely connected to the first, has been conducted on the technical-judicial aspects of transport. The aim of both studies was to offer useful instruments to decision makers to help them make efficacious interventions. The different interpretations of the basic concept of waste at an international, regional and national level, together with the lack of clearly defined borders between the concept of waste and that of goods, are weak points of the regulations. The unresolved problem in the initial part of the model affects all the phases of the transboundary movement of waste. In particular, the important phase of controls, which in itself is already difficult and costly, is unable to reach its objectives. Decision makers should first of all intervene by establishing a univocal definition of waste and goods. However, the technical-judicial problem can only be resolved by legal practitioners and technical experts in the sector who are known to be super partes at an international level. In particular, it is necessary to monitor the increasingly rapid technological evolution in order to be able to identify what is waste, or has become so and what are (or continues to be) goods, considering the various degrees of development throughout the planet. Only once these aspects have been clarified will a more efficacious control of all the elements that make up the chain be possible.
\end{abstract}

Keywords: Basel Convention, Rotterdam Convention, Stockholm Convention, Judicial Model, Hazardous Waste, PCBs 


\section{INTRODUCTION}

\subsection{The Problem}

The international movement of dangerous goods and dangerous waste is a matter of concern for the environment and human health, as well as for the economy. Illegal movements have an adverse effect on the environment, human health, trade and competition and put law-abiding businesses at an economic disadvantage. Illegal movements also undermine international policy and enforcement efforts.

\subsection{How the Problem Has Been Faced at an International Level}

The transboundary movement of dangerous goods and wastes has been considered in the international agenda since the eighties. The OECD member countries decided, in 1984, that the exportation and importation of hazardous waste should be controlled. The OECD developed eight legally binding instruments that were then adopted by the member countries. These form the basis of the Basel Convention, at the UNEP level, of other international Conventions (the Stockholm and Rotterdam Conventions), of Multilateral Environmental Agreements (MEAs) and of several European Community directives and regulations.

\subsection{The Basel Convention}

The Basel Convention on the Control of Transboundary Movements of Hazardous Wastes and their Disposal was adopted at the UNEP level and entered into force on 5 May 1992 (UNEP, 2011) (Basel Convention Secretariat, http://www.basel.int); on 1 January 2011, a total of 175 Parties were members of the Convention.

The Basel Convention also has clear links with regional hazardous waste regimes that were established in the 1990s (some in response to the failure of the Convention to ban exports from North to South) and in particular with the following two. The first, in order of time, is the Bamako Convention on the Ban of Imports to Africa and the Control of Transboundary Movement and Management of Hazardous Waste within Africa (BC, 2010) which prohibits the importation of hazardous waste into Africa (though it controls trade among parties by notification and consent). The Convention was adopted in Bamako, Mali, on January 30, 1991 and came into force in 22 April 1998. Only OAU countries can become parties of the Convention (on 2 September 2011, of the 53 countries that adhere to OAU, 34 have signed and 24 have ratified). The second, in order of time, is the Waigani Convention, the Convention to Ban the Importation of Hazardous and Radioactive Waste and to
Control the Transboundary Movement and Management of Hazardous Waste within the South Pacific Region. It was prepared for signature in Waigani, Papua New Guinea in 1995 and entered into force in 2001. The Secretariat of the Pacific Regional Environment Programme (SPREP, http://www.sprep.org; WC, 2007) serves as the Convention's Secretariat, while the Secretary General of the Pacific Islands Forum Secretariat serves as the Depositary. As of June 2008, there are 13 Parties; France, the Marshall Islands, the United Kingdom and the United States are eligible to join the Convention but have not yet done so. The Waigani Convention prohibits the importation of hazardous wastes into developing Pacific Island countries. The main difference between the Basel and Waigani Conventions is that Waigani Convention is administered within the Pacific Forum region. The Waigani Convention is also different from the Basel Convention in that it covers radioactive waste and covers the Economic Exclusion Zone (200 nautical miles) rather than the territorial sea (12 nautical miles) that is covered under the Basel Convention. As in the case of the Basel Convention, these regional agreements can assist the national implementation of environmentally sound waste management strategies. Moreover, the Basel Secretariat collaborates with the secretariats of these agreements (the Bamako Convention has no Secretariat and it is necessary to refer to Organization of African Unit, www.au.int (OAU), which is acting as a depositary) and shares knowledge on the institutional procedures and functions. Additionally, the Convention interacts with other international groups that are already established or are under negotiation, particularly in the field of chemical management.

\subsection{The Rotterdam and Stockholm Conventions}

Both the 1998 Rotterdam Convention (http://www.pic.int) (UNEPBC, 2011) on the Prior Informed Consent Procedure for Certain Hazardous Chemicals and Pesticides in International Trade and the 2001 Stockholm Convention (http://chm.pops.int) (UNEPSC, 2011) on Persistent Organic Pollutants (POPs) have close ties with the Basel Convention. Attempts are currently being made to co-ordinate the work of these different organizations in order to ensure coherency and avoid duplication, although each group complements the others by addressing different life-cycle aspects of a hazardous chemical, such as its production, use, trade, or disposal.

\subsection{The Failure of the Regulations Drawn up by the International Community}

Basically, after more than thirty years, it is necessary to consider that the regulating efforts set in 
motion by the International Community have failed to a great extent. It is recognized, from an international point of view, that economic factors and judicial aspects are behind this failure. The economic factors can be synthesized as follows. The relatively high labour costs of the treatment or disposal of waste in developed countries compared to countries like Africa and Asia are a strong factor for illegal movements from Western Countries to African and Asian Countries. Several waste streams are shipped to developing countries as 'second hand goods': the huge difference in prices between used and new products in these countries is one of the most important factors behind illegal movements. Chemicals that are banned in EU countries (in fact becoming waste) are sometimes not banned totally in countries outside Europe and can find legal (or illegal) use as normal products (e.g., CFCs or other ozone depleting substances). Some harmful substances, or goods which are forbidden and no longer allowed to be used and traded in Western countries are sometimes shipped illegally abroad to save treatment costs.

Instead, the judicial instruments prepared by the International Community deal with one single problem through two separate judicial-technical models. The first (and which is here examined) has the aim of regulating and controlling the transboundary movement of waste, regardless of the mode of transport. This model was introduced in the mid-eighties. The second judicial model, which is the subject of a companion paper (Carosso et al., 2012), concerns the regulation and control of international transport (by sea, rail, inland navigation, road and by air) and it was set up between the end of the fifties (except for inland navigation, which is much more recent) and the seventies. The transport model (especially by road or rail) suffers more from the particular nature of the regulations of each single State, with respect to the more harmonizing and coherent action of an international organization such as UNEP. Again, the intuition of the different countries concerning the necessity of a greater harmonization of the legislation, for both models, at an international level, in order to face global problems, has only recently emerged and is still a question of debate.

\subsection{Approach to the Problem}

A substantial agreement exists concerning the economic factors that have thwarted the regulating efforts of the International Community, while the debate on the same international regulation still remains open. Mathur and Siddharth (2009) and Sumit (2009) put emphasis on the hoary problem of the complex relationships between the rules of the free market of the
World Trade Organization (WTO) and the aforementioned MEAs that have the purpose of protecting the environment and human health. Other studies have been dedicated to more detailed problems, such as that by Fiore et al. (2008; 2012), Blengini et al. (2012). Here it was considered necessary to conduct an in depth investigation of the framework of the aforementioned International Conventions in order to verify whether and to what extent, these MEAs have a solid basis, to indicate a coherent path to follow, from the juridical point of view, along the entire chain and whether they offer possible suggestions to decision makers, concerning their intervention, at an international level. Doubts on some of the weak points of the judicialtechnical framework have already been raised on several occasions by Carosso (2008), pointed out his considerations with specific reference to Italian regulations and their derivations from secondary European law with reference to waste in general and to waste derived from the building industry as well as open air or underground excavations in particular. Therefore, it is on this basis that the judicial model of the transboundary movement of hazardous waste is examined and, in a companion paper, the technicaljudicial model of the multimodel transport of hazardous goods and waste (Carosso et al., 2012). The study of the technical-judicial model is conducted (1) in general and (2) focusing attention on the modality with which the controls are carried out. The examination of the former model is concentrated on the 3 fundamental Conventions (Basel, Rotterdam and Stockholm), on their enclosures and on the technical-judicial references they refer to. As far as the controls are concerned, attention has been focused on the "Draft revised versions of the forms for the notification document and the movement document and related instructions" (12 September 2006, at http://www.basel.int). An examination of the specific notifications and movement documents that are compatible with the three previously mentioned instruments makes it possible to follow hazardous waste from its origin till its final destination. The forms take into account not only some specific requirements set out in the Basel Convention, but also those established in the OECD Decision texts (http://webnet.oecd.org/oecdacts) and in the EU Regulation (http://eur-lex.europa.eu).

The study continues, but also in the companion paper, taking into consideration some substances covered by all three organizations. Polychlorinated byfenils (PCBs), for which the Basel Convention has examined the management of waste PCBs, while the trade of PCBs is regulated by the Rotterdam Convention and PCBs are controlled-with the aim of their elimination-by the Stockholm Convention, are examined as a practical case. 
This category of materials was chosen since materials consisting of, containing or contaminated with PCBs, PCTs or PBBs are found in a number of physical forms, including: capacitors, circuit breakers, electrical cables, electric motors, electromagnets, heat transfer equipment, hydraulic equipment, switches, transformers, vacuum pumps, voltage regulators, etc. In this way, different cases of a single category which can be considered, from a judicial point of view, either products or waste, can be examined.

\section{MATERIALS AND METHODS}

\subsection{The Basel Convention on the Transboundary Movemement of Hazardous Waste and its Disposal}

Article 1 (The scope of the Convention) of the Basel Convention points out the waste types that are subject to the Basel Convention. Sub-paragraph 1 (a) of the Article sets forth a two-step process to determine whether a "waste" is a "hazardous waste" and subject to the Convention: first, the waste must belong to any category contained in Annex I of the Convention ("Categories of Wastes to be Controlled") and second, the waste must possess at least one of the characteristics listed in Annex III of the Convention ("List of Hazardous characteristics"). Annex I wastes are presumed to exhibit an Annex III hazardous characteristic such as H11 "Toxic (Delayed or Chronic)", H12 "Ecotoxic", or H6.1 "Poisonous (Acute)", unless they can be shown to not exhibit such characteristics through "national tests". National tests may be useful to identify a particular hazard characteristic listed in Annex III, until such a time the hazardous characteristic is defined clearly. Guidance papers are currently being developed under the Basel Convention for each Annex III hazardous characteristic.

List $A$ in Annex VIII describes wastes that are "characterized as hazardous under Article 1 paragraph 1(a) of this Convention" although "Designation of a waste to Annex VIII does not preclude the use of Annex III (hazard characteristics) to demonstrate that a waste is not hazardous" (Annex I, paragraph (b)). List B in Annex IX lists wastes which "shall not be wastes covered by Article 1, paragraph 1 (a), of this Convention unless they contain Annex I material to an extent that causes them to exhibit an Annex III characteristic"

\subsection{Competent Authority and Focal Point}

Pursuant to article 5 of the Basel Convention, the Parties are required to designate or establish one or more competent authorities and one focal point to facilitate the implementation of the Convention.
A "competent authority" means a governmental authority that has been designated to be responsible, within such geographical areas as the Party may think fit, for receiving notifications of transboundary movements and any related information and for responding to such notifications (article 2).

A "focal point means" the entity of a Party responsible for receiving and submitting information to other Parties, as laid down in articles 13 and 16 of the Convention (article 2).

\subsection{National Definition of Hazardous Wastes}

Pursuant to article 3, paragraph 1 of the Basel Convention, the Parties must inform the Secretariat of the Basel Convention of wastes other than those listed in Annexes I and II which are considered or defined as hazardous under their national legislation and of any significant changes in national definitions.

Information should also be forwarded concerning any requirements about the transboundary movement procedures applicable to those wastes. Information reported using a duly completed form will be regarded as formal notification, pursuant to article 3 and will be transmitted by the Secretariat to all the Parties and Signatories. A Party that wishes such wastes to be governed by particular obligations or procedures for the transboundary movement of wastes, provided under the Convention, such as, for example, the Prior Informed Consent (PIC) procedure (article 4, paragraph 1 (c)), must send specific notification that indicates that it is made under articles 3 and/or 13, paragraph 2 (b), to the Secretariat for transmittion to all the Parties. Once such a communication has been transmitted, the obligations that arise under the Convention will apply to those wastes.

\subsection{Prohibition of the Importation of Hazardous Wastes}

In general, shipments to and from non - Parties are illegal, unless there is a special agreement. Art. 4, par. (1) of the Convention states that Parties exercising their right to prohibit the importation of hazardous wastes or other wastes for disposal shall inform the other Parties, through the Secretariat, of their decision, pursuant to Article 13, paragraph (2) (c).

Such communications may relate to wastes included in Annex I and Annex II, as well as those ruled by the Basel Convention through a national notification, pursuant to Article 3. Parties are prohibited from exporting the wastes mentioned in art. 1 of the Convention for disposal within the area south of latitude $60^{\circ}$ (Article 4.6), whether or not such wastes are subject to transboundary movement. 


\subsection{Environmentally Sound Management (ESM)}

The Convention obliges its Parties to ensure that wastes are managed and disposed of in an Environmentally Sound Manner (ESM). This provision (article 4, paragr. 8) was signed by 170 countries, of which three (Afghanistan, the United States and Haiti) have not yet ratified their membership.

\subsection{The Ban Amendment}

The amendment to the Basel Convention (Ban Amendment) adopted in 1995 during the third meeting of the Conference of the Parties on its Decision III/1, bans hazardous waste exports from what are known as Annex VII countries (Basel Convention Parties that are members of the EU, OECD and Liechtenstein) to nonAnnex VII countries (all other Parties in the Convention). However, the Ban Amendment has not yet entered into force because entry into force can only take place upon ratification by at least three-quarters of the Parties, which has not yet taken place.

\subsection{The Rotterdam Convention}

The Rotterdam Convention on the Prior Informed Consent (PIC) Procedure for certain hazardous Chemicals and Pesticides in international trade was adopted at the Diplomatic Conference held in Rotterdam on 10 September 1998. The Decisions of the Convention entered into force on 24 February 2004 and became legally binding for its Parties. In 2011, a total of 144 Parties (countries or regional economic integration organizations) ratified, accepted, approved or acceded to the Convention. Each Party had to designate one or more national authorities (the Designated National Authorities (DNAs)), which are the primary contact points for matters related to the operation of the Convention and are authorized to perform the administrative functions required by the Convention. DNAs are also the key contact points for matters related to the Convention for other Parties and the Secretariat. The Convention creates legally binding obligations for the implementation of the Prior Informed Consent (PIC) procedure.

The Convention covers pesticides and industrial chemicals that have been banned or severely restricted for health or environmental reasons by the Parties and which have been notified by the Parties for inclusion in the PIC procedure. One notification from two specified regions triggers a process of considering the addition of a chemical to Annex III of the Convention. Severely hazardous pesticide formulations that present a risk under conditions of use in developing countries or countries with economies in transition may also be proposed for inclusion in Annex III.
Once a chemical is included in Annex III, a "Decision Guidance Document" (DGD) containing information on the chemical and the regulatory decisions to ban or severely restrict the chemical for health or environmental reasons, is circulated to all the Parties.

The Parties have nine months to prepare a response concerning the future importation of the chemical. The response can consist of either a final decision (to allow importation of the chemical, not to allow importation, or to allow importation, subject to specified conditions) or an interim response. Decisions by an importing country must be trade neutral (that is, decisions must apply equally to domestic production for domestic use as well as to imports from any source).

The import decisions are circulated and the exporting country Parties are obligated, under the Convention, to take appropriate measures to ensure that exporters within its jurisdiction comply with the decisions.

It should be noted that industrial chemical management covers a wide range of hazardous chemicals that do not fall within the purview of the Convention.

\subsection{The Stockholm Convention on Persistent Organic Pollutants (POPs)}

Scientists have recognized that POPs share four main properties that cause significant concern:

- They are extremely toxic to human beings and the environment

- They do not degrade and may remain intact in the environment for many years

- They accumulate in the fatty tissue of humans and other living organisms in both terrestrial and aquatic ecosystems and exist at higher concentrations in the food chain

- They are transported throughout the environment and across boundaries through soil, water and especially air

The Stockholm Convention on Persistent Organic Pollutants (POPs) was adopted on 22 May 2001 and entered into force on 17 May 2004. The Convention text was amended in 2009 to include nine new POPs that had been added to Annexes A, B and C. On 26 August 2010, these amendments entered into force for 151 of the 152 Parties of the Stockholm Convention that did not submit a notification or a declaration in accordance with paragraphs 3 and 4 of Article 22 of the Convention. Of all the Parties of the Stockholm Convention, only New Zealand has not accepted the amendments.

Countries that became Parties of the Stockholm Convention, following the adoption of these amendments, are bound to the whole of the Convention as amended. 
Annex a lists the POPs for which the Parties must take measures to eliminate their production and use and includes specific exemptions for the production or use that are only applicable to the Parties that have registered for these exemptions. Some of the POPs listed in Annex A are aldrin, chlordane, chlordecone, dieldrin, endrin, heptachlor. hexabromobiphenylm, Hexachlorobenzene (HCB), mirex, Polychlorinated Byfenils (PCBs) and toxaphene.

Annex B deals with restrictions on the production and use of DDT and perfluorooctane sulfonic acid, its salts and perfluorooctane sulfonyl fluoride. These restrictions are subject to any applicable acceptable purposes and/or specific exemptions listed in the Annex that apply. The Conference of the Parties (COP) continues to allow the use of DDT for disease vector control, as recommended by and under the guidance of, the World Health Organization (WHO).

Annex $\mathrm{C}$ includes POPs for which the Parties must take measures to reduce their unintentional release, with the objective of continuing to minimize and eventually eliminate them where feasible. Some of these POPs are furans and dioxins, hexachlorobenzene (HCB), PCBs as by-products and polychlorinated dibenzo-p-dioxins and polychlorinated dibenzofurans (PCDD/PCDF).

In order to ensure the environmentally sound management of stockpiles, wastes and products as well as articles that, upon becoming wastes, consist of, contain or are contaminated by POPs, the Convention has set the following obligations for its Parties:

- To develop and implement strategies to identify stockpiles, products and articles in use and wastes containing POPs

- To manage stockpiles in a safe, efficient and environmentally sound manner until they are deemed to be wastes

- To take measures to handle, collect, transport and store wastes in an environmentally sound manner and dispose of wastes in a way that destroys the POP content.

The obligations relevant to import/export activities only cover intentionally produced POPs.

The importation of the POPs that are included in the Convention is only allowed for the purpose of environmentally sound disposal or for a pre-determined use allowed by the Convention for the importing Party. All other imports are prohibited. The exportation of POPs included in the Convention is only allowed for the purpose of environmentally sound disposal or for a predetermined use allowed by the Convention for the importing Party. All other exports between Parties are prohibited. Export is also allowed to a State that is not party to the Convention, if the State provides an annual certification in which it specifies the intended use of the chemical and includes a statement in which it states its intention to comply with the provisions of the Convention on the management of wastes and stockpiles and to comply with requirements for DDT production and use, if applicable.

\subsection{Control of Waste Exports and Imports, Notification and Movement Document}

International instruments have been established to control the exportation and importation of wastes that may pose a risk or a hazard to human health and the environment. As previously indicated, two of the most influential instruments are the UNEP Basel Convention and the OECD Decision; in addition to these two instruments, the Member States of the EU are obliged to comply with the relevant EU Regulations.

The Basel Convention and the EU Regulation concern the international movement of waste, whether it is destined for disposal or recovery, whereas the OECD Decision only concerns the movement of waste destined for recovery operations within the OECD area.

These forms include both the terms, "disposal" and "recovery", due to differences in the definition of the terms by each instrument. The national competent authorities in the exporting state are responsible for providing and issuing the forms for the Notification and Movement Documents (both paper and electronic versions). When doing so, they use a numbering system, that allows a particular consignment of waste to be traced. The numbering system should be prefixed with the country code, which can be found in the ISO Standard 3166-abbreviation list.

\subsection{The Notification Document}

The Notification Document has the purpose of providing the information, to the competent authorities of the concerned countries, of the need to assess the acceptability of the proposed waste movement. The Document includes a space in which to acknowledge receipt of the notification by the relevant competent authority(ies) and, when required, to consent in writing to the movement.

The procedure consists of the following steps:

- The exporter/generator of the wastes and the proposed disposer draw up a contract that specifies that the wastes will be disposed of in an environmentally sound manner

- The exporter/generator notifies the Competent Authorities of the State from which the wastes are to be exported about the proposed shipment. The 
exporting State then informs the importing State about the proposed movement of hazardous wastes, or other wastes, by means of a notification document

- Before any movement begins, the Competent Authorities of the importing State must provide the exporting State with written consent and must confirm the existence of a contract between the generator/exporter and the disposer that specifies environmentally sound management of the wastes. Similar notifications must be sent to the Competent Authorities of any proposed States of transit, which must also provide written consent before the movement may commence. However, the consent of the State of transit is not required, if it has waived its right to prior written consent and has notified the other Parties to the Convention to that effect.

- Upon receipt of the written consent from the importing State and any states of transit, the Competent Authorities of the exporting State may permit the shipment to start. The disposer must inform the exporter/generator and the Competent Authorities of the exporting State when it has received the wastes and, in due course, when the disposal has been completed in accordance with the terms of the disposal contract. The exporting State is obligated to re-import the wastes if the disposal cannot be completed in accordance with the terms of the contract, unless alternative arrangements can be made for their disposal in an environmentally sound manner.

\subsection{The Movement Document}

The Movement Document has to travel with the consignment at all times, from the moment it leaves the waste generator to its arrival at the disposal/recovery facility in another country. Space is provided in the Document for detailed information on the first and any subsequent carriers of the consignment. In addition, Article 6.9 of the Basel Convention requires each person who takes charge of a transboundary movement to sign the movement document, either upon delivery or receipt of the waste in question. There are also spaces to record the passage of the consignment through the Customs offices of all the countries concerned. Although not strictly required by the international instruments, some countries, because of national legislation, may require such procedures and information to ensure proper control. Finally, the Document should be used by the disposal/recovery facility to certify that the waste has been received and that the recovery/disposal operation has been completed.

Bearing in mind the previously mentioned differences, the wording used hereafter refers to the definition in the Basel Convention conditions and procedures. The forms are in general the same and are accepted under the Basel Convention, OECD Decision and EU Regulations.

\subsection{Conditions for Movement of Wastes}

Wastes that fall under the Basel Convention can only be shipped across international boundaries if certain conditions are met and certain procedures are adopted. Normally, the Competent Authorities assess whether the conditions have been met and are responsible for ensuring that the procedures are followed.

The Parties are obliged to take appropriate measures to ensure that the transboundary movement of hazardous waste and other waste is allowed only if:

- The exporting State does not have the technical capacity and the facilities, capacity or suitable disposal sites needed to dispose of the wastes in question in an environmentally sound manner; or

- The wastes in question are required as raw material for recycling or recovery industries in the importing State

The Convention permits the Parties to adopt other applicable criteria from time to time. Such criteria are normally found in the decisions adopted by the Conference of the Parties (COP), which are binding for all the Parties.

However, as already mentioned, the Convention requires that the "environmentally sound management" (ESM) standard is met. Article 2.8 defines this standard as "taking all practical steps to ensure that the waste is managed in a manner which will protect human health and the environment against the adverse effects which may result from such waste". The requirements to meet the standard of ESM may change, from time to time, on the basis of the current scientific, technical, economic and environmental information.

\section{RESULTS}

\subsection{The Legal Bodies Involved}

Glancing through the notification/movement documents that must accompany waste during all transboundary movements, from its place of origin to its destination and which are used for the formal controls and the traceability of the movements, it has emerged that in boxes 20/22 (which do not need to be filled in completely), there is a considerable number of legal parties involved. These parties range from the creator of the waste to the exporter-notification figure, from the importer-consignee to the Customs Offices and to the competent Authorities of the countries involved, 
including any countries the waste passes through. The documents must supply- in a very synthetic manner- all the previously mentioned information. Any other information should be noted in a very synthetic way and, if pertinent, can be divided into two parts: one concerns the vector(s) foreseen and the methods and means of transport (for this aspect reference can be made to the companion paper). In what follows, attention will be focused on the identification of waste, on its denomination, on its hazardous characteristics and on what could be its final destination (disposal/recovery), information that is needed to fill in the other boxes in the documents.

\subsection{The Definition of Waste}

The Basel, Rotterdam and Stockholm Parties, OECD Member countries and EU Member States all have not only different definitions of the word "waste", but also different understandings. Consequently, different decisions may be made in different countries about the status of the same material and therefore, the same material may be regarded as waste in one country but as a commodity or raw material in another country.

Many difficulties arise about the definition of waste and its practical consequences. Many documents have been published on this topic: reference can be made to the OECD Document (1998) and the Communication 2007/59 (from the European Commission) on the Interpretative Communication on waste and by-products CEC, 2007).

In general, the definition of waste is applied by the competent authorities, on a case-by-case basis, when waste shipment or permit decisions are made. A number of issues have arisen in relation to the interpretation of this case-by-case definition. One of these is related to the distinction between materials that are not the main objective of a production process, but which can be considered as non-waste by-products and those that should be treated as wastes. In reality, there is not a black and white distinction, but rather a wide variety of technical situations with widely differing environmental risks and impacts and a number of grey zones. However, for the purposes of applying international environmental legislation, it is necessary to draw a clear line between the two legal situations on a case by case basis-waste or not waste. It is this distinction that has on occasions proved difficult to apply.

The Basel Convention defines wastes as "substances or objects which are disposed of or are intended to be disposed of or are required to be disposed of by the provisions of national law".

In a similar manner, the OECD Decision defines wastes as "substances or objects which:
- Are disposed of or are being recovered or

- Are intended to be disposed of or recovered or

- Are required, by the provisions of national law, to be disposed of or recovered".

European Regulation 2006/1013 (ECOLEX, 2006), on the shipment of wastes, defines waste (directive 2008/98/EC, art. 3, par. 1) as "any substance or object which the holder discards or intends to or is required to discard" (ECOLEX, 2008).

Radioactive wastes or substances-which are not considered in this study-are excluded from the cited legislations.

The European Court of Justice (ECJhttp://curia.europa.eu) has stressed, on several occasions, that whether a material is a waste or not depends on the specific factual circumstances and that the decision should therefore be taken by the competent authorities on a case-by-case basis. Finally, it is important to note that even when a particular material satisfies the tests set out by the ECJ in order to be considered as a non-waste, if it is in practice discarded, it should be considered and treated as waste.

\subsection{The Definition of Hazardous Waste}

Once a material is defined as waste, several difficulties arise in distinguishing hazardous from nonhazardous material. It is sufficient to read the aforementioned related definition of the Basel Convention to understand that a number of ambiguities exist.

In general, the principle holds that 'hazardous waste' means waste which displays one or more of the hazardous properties listed from H1 ("Explosive': substances and preparations which may explode under the effect of flame or which are more sensitive to shocks or friction than dinitrobenzene") to H15 ("Waste capable, by any means, after disposal, of yielding another substance, e.g. a leachate, which possesses any of the previous listed characteristics"). There are 15 classes of hazard, some of which are further sub-dived into sub-classes: sometimes the insertion into one class or another can be difficult for a determined waste and it is often necessary to refer to the hazard class of the material when it was still considered goods in order to assign the $\mathrm{Hi}$ code.In this context, the aforementioned EU directive, 2008/98, foresees that the attribution of hazardous properties, that is, "toxic" (and "very toxic"), "harmful", "corrosive", "irritant", "carcinogenic", "toxic to reproduction", "mutagenic" and "eco-toxic" should be made on the basis of the criteria laid down by legislation on the classification, labeling and packaging of chemical substances and mixtures. It is sometimes necessary to conduct laboratory tests for which there are still no 
univocal agreements. Certain classes (e.g. H11 for toxic substances with delayed or chronic effects) are difficult to classify because there is a lack of scientific knowledge about them or they it is not universally accepted.

Finally, it is necessary to recall that some wastes that are considered hazardous in the legislation of an importing/exporting country might not be considered hazardous in the legislation of the corresponding exporting/importing country.

\subsection{The Definition of Disposal and Recovery}

The Basel Convention defines "disposal" (Article 2.4) as "any operation specified in Annex IV" and disposer "(Article 2.19) as "any person to whom hazardous wastes or other wastes are shipped and who carries out the disposal of such wastes".

In Annex IV of the Basel Convention, 15 operations are listed from D1 to D15 as "Operations which do not lead to the possibility of resource recovery, recycling, reclamation, direct re-use or alternative uses", plus 13 (from R1 to R13) "Operations which may lead to resource recovery, recycling reclamation, direct re-use or alternative uses"

The uncertainty is only overcome if one also reads the text and Annex of the Basel Convention very carefully: misleadings can arise because only the term "disposal" is considered in the text of the Basel Convention, while "recovery" is never defined. The term "disposal", in fact, covers both D1-D15 and R1-R13.

In their Annexes, in the OECD Decision (OECD, 2008) and in EU Regulation 2006/1013 on shipments of waste (ECOLEX, 2006), the terms "disposal" and "recovery" are clearly distinguished.

In the OECD Decision, disposal operations are specified in two separated Lists: Appendix 5.A for disposal operations and Appendix 5.B for recovery operations. A Recovery Facility is defined as "a facility which, under applicable domestic law, is operating or is authorised or permitted to operate in the importing country to receive wastes and to perform recovery operations on them".

In EU legislation, "disposal" means "any operation which is not recovery even where the operation has, as a secondary consequence, the reclamation of substances or energy. Annex I sets out a non-exhaustive list of disposal operations".

'Recovery' means "any operation the principal result of which is waste serving a useful purpose by replacing other materials which would otherwise have been used to fulfil a particular function, or waste being prepared to fulfil that function, in the plant or in the wider economy. Annex II sets out a non-exhaustive list of recovery operations".

\section{DISCUSSION}

\subsection{Identification of Waste-in General}

The identification of waste involves the detection of its denomination, its composition, its characteristics and its pertinent codes. This kind of identification is reported in boxes 12, 13 and 14 of the notification and movement document.

Box 12: Give the name(s) by which the material is commonly known and the names of its major constituents (in terms of quantity and/or hazard) and their relative concentrations, if known. In the case of a mixture of wastes, provide the same information for the different fractions and indicate which fraction(s) is/are destined for recovery. A chemical analysis of the composition of the waste may be required, in accordance with national legislation. Attach further information in an annex if necessary.

Box 13:Indicate the physical characteristics of the waste at normal temperature and pressure, using the codes provided in the list of abbreviations and codes, following the form of the Notification Document.

Box 14: Give the code that identifies the waste according to the Basel Convention (in i) and, where applicable, to the OECD Decision (in ii) and to other accepted classification systems (in iii to xii). According to the OECD Decision, only one waste code (in i or ii) should be given, except in the case of mixtures of wastes for which no individual entry exists. In this particular case, the code of each fraction of the waste should be provided in order of importance (in an annex if necessary):

- Basel Annex VIII code(s) for wastes subject to control under the Basel Convention and the OECD Decision (see Part I of Appendix 4 in the OECD Decision); or Basel Annex IX code(s) for wastes not usually subject to control under the Basel Convention and the OECD Decision but which, for a specific reason such as contamination by hazardous substances or different classification according to national regulations, are subject to control (see Part I of Appendix 3 in the OECD Decision). Basel Annexes VIII and IX can be found in the text of the Basel Convention as well as in the Instruction Manual available from the Secretariat of the Basel Convention.

- For OECD member countries, OECD code(s) for wastes listed in Part II of Appendices 3 and 4 of the 
OECD Decision, i.e. wastes that have no equivalent listing in the Basel Convention or that have a different level of control under the OECD Decision from the one required by the Basel Convention.

- For EU member states, code(s) of the EU list of wastes (Decision 2000/532/EC as amended).

- And v) When applicable, national identification code(s) by which the waste is designated in the exporting country and, if known, in the importing country.

- If useful or required by relevant competent authorities, add here any other code or additional information that could facilitate the identification of the waste.

- If applicable, Y-code(s) which agree(s) with the relevant "Category(ies) of wastes to be controlled" (see Annex I of the Basel Convention and Appendix 1 of the OECD Decision) and/or the "Category of wastes requiring special consideration" given in Annex II of the Basel Convention. "Y" codes are not required by the OECD Decision with the exception that, if the waste shipment relates to one of those two "categories requiring special consideration" under the Basel Convention (Y46 and Y47 or Annex II wastes), the Basel Y category should be indicated.

- H-code(s), i.e. the code(s) indicating the hazardous characteristic(s) exhibited by the waste (see codes and characteristics in the list of abbreviations and codes, following the form of the Notification Document).

- UN class(es) which indicate(s) the hazard characteristic of the waste according to the UN classification and is (or are) required to comply with international rules for the transport of hazardous materials (see the companion paper).

- and (xi) UN Number(s) and UN shipping name(s) which are used to identify the waste according to the UN classification and are required to comply with international rules for the transport of hazardous materials (see the companion paper).

- (xii) If applicable, customs code(s), which allow(s) the identification of the waste by the Customs. See the list of codes and commodities in the "Harmonised commodity description and coding system", which is generally referred to as "Harmonized System" or simply "HS" is a multipurpose international product nomenclature developed by the World Customs Organization (WCO-http:// http://www.wcoomd.org). The HS Coding System comprises about 5,000 commodity groups, each identified by a six-digit code.

\subsection{Identification of Waste-the Case of PCBs}

It should first be noted that a significant fraction of the total national inventories of PCBs, PCTs and PBBs may be in the hands of small business owners and homeowners in small quantities (for example, in PCB fluorescent light ballasts, other small electrical devices, heat exchangers and heaters containing PCB or PCT fluids, PBBs in fire suppression systems, small containers of pure products and small stockpiles). It is difficult for those who have small quantities to dispose of these materials: costs may be prohibitive and logistical considerations may prevent or discourage waste pick-up (e.g., no industrial waste pick-up allowed or available in a residential neighbourhood); furthermore, the regulatory situation may require that these individuals should be registered waste generators with the obvious resulting control problems.

It should be taken into account in the identification process, that PCBs, PCTs and PBBs can be found in a number of devices and locations, including Electric utilities (transformers, capacitors, switches, voltage regulators, circuit breakers, light ballasts and cables), Industrial facilities (transformers, capacitors, voltage regulators, circuit breakers, light ballasts, heat transfer fluids, hydraulic fluids and fire suppression systems), Underground mining operations (hydraulic fluids and earthing coils).

It should be noted that even experienced technicians may not be able to determine the nature of an effluent, substance, container or piece of equipment just by its appearance or marking. PCB equipment, for example, is usually not labelled according to the type of dielectric fluid it contains. Experienced inspectors may be able to determine the original contents from other information on the nameplate, or by contacting the manufacturer.

Information on the production, use and waste types may be useful to identify PCBs, PCTs and PBBs.

Finally, it is impossible to draw up a complete inventory of all PCBs, PCTs and PBBs, mainly because of the dispersed nature of the uses of these chemicals (e.g., in inks, plasticizers, paint, flame retardants in small components and lubricants).

Annex I to the Basel Convention lists some of the wastes that may consist of, contain or be contaminated with PCBs, PCTs or PBBs. Annex VIII, in which some waste categories are in particular applicable to PCBs, PCTs or PBBs, should also be considered. Such a classification depends to a great extent on the fact that they possess some of the characteristics mentioned in Annex III. Although some entries of the Annex refer to waste for a concentration level of $50 \mathrm{mg} \mathrm{kg}^{-1}$ (since it is considered to be an internationally practical level) or more, many individual countries have established lower regulatory levels (e.g., $20 \mathrm{mg} \mathrm{kg}^{-1}$ ). List A in Annex VIII to the Basel Convention includes a number of wastes or waste categories that have the potential of containing or be contaminated with PCBs, PCTs or PBBs. 


\subsection{Environmentally Sound Management (ESM) in General}

The information relative to environmentally sound management is given in boxes 10 and 11 .

Box 10: Give the required information on the destination of the shipment, by first ticking the appropriate type of facility: disposal versus recovery. The registration number should be given where applicable. If the disposer or recoverer is also the importer, note here "Same as box 2". If the disposal/recovery operation is a D13-D15 or R12/R13 operation, the facility performing such an operation should be mentioned in box 10 as well as the location where such an operation will be effectively performed. In this case, also the corresponding information on the subsequent facility (ies), where any subsequent R12/R13 or D13-D15 operations and the D1D12 or R1-R11 operation(s) take(s) place or may take place, should also be provided as an attachment. Provide information on the actual site of disposal/recovery when it is different from the address of the facility.

Box 11: Indicate the type of recovery or disposal operation using R-codes or D-codes, which are provided in a list of abbreviations and codes, following the form of the Notification Document. The OECD Decision only covers transboundary movements of wastes destined for recovery operations (R-Codes) within the OECD area. If the disposal/recovery operation is a D13-D15 or R12/R13 operation, attach corresponding information on the subsequent operations (any R12/R13 or D13-D15 as well as D1-D12 or R1-R11). The technology to be employed should also to be indicated. Specify the reason for the exporting (however, this is not required by the OECD Decision).

\subsection{The Environmentally Sound Management (ESM) of PCBs}

Articles 3 and 6 of the Stockholm Convention provisions and Annex A concern intentionally produced PCBs whose production and use should be eliminated. Annex A, Part II outlines specific requirements with respect to PCBs: for example, each Party, with regard to the elimination of the use of PCBs in equipment, subject to review by the Conference of the Parties, will be subjected to take action by 2025 , in accordance with the properties of the Annexes.

As wastes, PCBs should be managed and disposed of in an environmentally sound manner The term "Environmentally Sound Management" (ESM) is not defined in the Stockholm Convention.
Environmentally sound methods for the disposal of wastes consisting of, containing or contaminated with PCBs, however, is under determination by the Conference of the Parties in cooperation with the appropriate bodies of the Basel Convention.

Although a format has already been hypothesized to define ESM, it should be pointed out that the timing of the phase-out of PCBs (and to a lesser extent PCTs and PBBs) will probably be the most critical legislative concern for most countries, given that most countries already have some form of legislative framework to deal with PCBs.

\section{CONCLUSION}

\subsection{What the Decision Makers Can Do}

The attention of the decision makers should be concentrated on two fundamental aspects.

The first concerns the difference between goods and waste and it is concerning this point that the general weakness of the legislation emerges. This problem, which is dealt with in the first stage of the chain, if not resolved, is trailed along till the end of the chain. Any material whatsoever, if not assigned correctly, from the judicial point of view, can become uncontrollable. It therefore becomes easy, for organized crime, to become involved already in the first stages in activities connected to the transboundary movement of waste. If the identification itself between waste and non waste is compromised, it becomes easy for organized crime to ship waste while falsely claiming that they are dealing with second-hand goods, which are therefore not subject to waste regulations. It is common practice to falsify documentation regarding waste loads or to not declare waste on the documentation, or even to transport waste without notifying the authorities about the source and destination when such a notification is necessary.

The second aspect regards the controls that should be carried out. The different interpretations of "waste" and "product", even by the authorities and enforcement agencies of the exporting and importing countries, undermine the credibility of the international regulations themselves.

Of course, there are many other problems that decision makers should consider. For instance, as far as hazardous characteristics are concerned, the problem can become particularly serious and relevant for the environment and health. Therefore, mixing certain types of waste or classifying hazardous waste as nonhazardous, or even joining waste and dangerous products in the same transboundary movement is not so difficult. There are also other uncertainties connected to the disposal/recovery aspects, which are considered in different ways by the Basel Convention and by the OECD. The connections between the Basel and Stockholm Conventions often seem complex and 
contradictory and these also become the topics of nonunivocal interpretation.

An improvement in the technical-judicial model can be obtained through the joint work of experts from both a judicial background and from the technical field. The two forms of competence should be placed side by side, on condition that a priority exists, that is, until the difference between waste and goods is clear for everybody concerned, the various steps in the transboundary movement of waste will suffer negatively. The experts should be chosen from among high profile and super partes technical and judicial experts who are recognized as such at an international level: these experts should answer for their actions to the international organizations since a similar activity, in order to be efficacious, should be conducted at the UN level.

While working on this nevertheless fundamental point, something could also be done in the short term, as far as controls are concerned. One or more versions of the Green Customs Initiatives (GCI) (UNEP, 2008), which were launched in 2001 by the World Customs Organization (WCO), could be re-proposed, but with greater intensity. The GCI was the first relevant step for those countries that are involved in treaties with traderelated provisions, such as the Basel Convention, the Rotterdam Convention, the Stockholm Convention, the Cartagena Protocol on Biosafety, the Convention on the Prohibition of the Development, Production, Stockpiling and use of Chemical Weapons and on Their Destruction, the Convention on International Trade in Endangered Species of Wild Fauna and Flora (CITES) and the Montreal Protocol on Substances that Deplete the Ozone Layer (ODS).

As far as the work of Customs and border control officers is concerned, a series of collaborative activities could be proposed which could include workshops, training material and joint actions by partner organizations with the aim of raising the awareness of Customs officers on environmental issues. In 2006, the Sky-Hole Patching Project was launched jointly by 20 Customs administrations in the Asia Pacific region and was supported by the WCO Asia Pacific Regional Intelligence Liaison Office (RILO) and the UNEP regional office in Thailand. This regional project led to the seizure of 155 tons of Ozone Depleting Substances (ODS) and 116 seizures of almost 20,000 tons of hazardous waste, ranging from e-waste to used clothing and waste oil.

\section{REFERENCES}

BC, 2010. Bamako convention on the ban of the import into Africa and the control of transboundary movement and management of Hazardous Wastes within Africa. The African Union Commission.
Blengini, G.A., M. Fanton, M. Busto, G. Genon and M.C. Zanetti, 2012. Participatory approach, acceptability and transparency of waste management LCAs: Case studies of Torino and Cuneo. Waste Manag., DOI: 10.1016/j.wasman.2012.04.010

Carosso, G., 2008. Normativa Ambientale in Progress. 1st Edn., Scriptaweb, ISBN: 9788863810042

Carosso, G., C. Luceri and P. Oreste, 2012. The international multimodal transport of hazardous goods and waste. Am. J. Environ. Sci., 8: 443-453. DOI: 10.3844/ajessp.2012.443.453

CEC, 2007. On the Interpretative Communication on Waste and By-products: Communication from the Commission to the Council and the European Parliament. 1st Edn., Office for Official Publications of the European Communities, Luxembourg, pp: 13.

ECOLEX, 2006. Regulation (EC) No. 1013/2006 of the European Parliament and of the Council on shipments of waste. Official J. Eur. Union.

ECOLEX, 2008. Directive 2008/98/EC of the European Parliament and of the Council on waste and repealing certain Directives. Official J. Eur. Union.

Fiore, S., B. Ruffino and M.C. Zanetti, 2008. Waste Characterization in Steel Casting and Recycling Opportunities in Europe. Am. J. Applied Sci., 5: 512-518. DOI: 10.3844/ajassp.2008.512.518

Fiore, S., B. Ruffino and M.C. Zanetti, 2012. Automobile shredder residues in Italy: Characterization and valorization opportunities. Waste Manage., 32: 15481559. DOI: 10.1016/j.wasman.2012.03.026

Mathur, A. and D. Siddharth, 2009. Multilateral Environmental Agreements versus world trade organization system. Am. J. Econ. Bus. Admin., 1: 219-224. DOI: 10.3844/ajebasp.2009.219.224

OECD, 2008. Decision C (2001)107/FINAL of the Council concerning the control of transboundary movements of wastes destined for recovery operations. Organisation for Economic Co-operation and Development.

Sumit, K.J., 2009. Development or the environment. Am. J. Econ. Bus. Admin., 1: 257-262. DOI: 10.3844/ajebasp.2009.257.262

UNEP, 2008. Green customs guide to multilateral environmental agreements. United Nations Environment Programme.

UNEP, 2011. Food and Agriculture Organization (FAO) and rotterdam convention. Organisation for Economic Co-operation and Development.

UNEPBC, 2011. Basel convention on the control of transboundary movements of hazardous wastes and their disposal. UNEPBC.

UNEPSC, 2011. The stockholm convention on persistent organic pollutants. UNEPSC.

$\mathrm{WC}, 2007$. The waigani convention to ban the importation into forum countries of hazardous and radioactive wastes and to control the transboundary movements and management of hazardous wastes within the. Waigani Convention. 